from much pain. Double strength Locke's solution was then ordered and in three days' time the patient reported at the hospital when it was found that the cornea was almost completely covered with epithelium and only stained in one small area. I have also treated with satisfactory results indolent corneal ulcers.

As the cornea depends for its nourishment on the lymphatic supply I think it quite reasonable to assume that a solution having a similar composition to lymph, as far as the mineral salts are concerned at any rate, will have a beneficial action when applied frequently to the cornea. The beneficial action being to hasten the reparative processes will chiefly manifest itself in the superficial layers of the cornea.

\title{
RETROBULBAR NEURITIS ASSOCIATED WITH SINUSITIS, OPERATION, RECOVERY
}

\author{
BY \\ W. S. ThaCKER-NeVILle \\ EAR, THROAT AND EYE DEPARTMENT, GENERAL HOSPITAL, DARLINGTON
}

Female, aged 21 years (E.H.) was seen August 11, 1926. Patient complained of right eye being blind for one month. The patient said that a month ago she had pain on moving the eyeball. This commenced suddenly and was also associated with an acute nasal catarrh, and the condition lasted three weeks. During this time she had difficulty in looking inwards. Her grandfather became blind at the age of 38 years. On examination :-without lenses : V.O.D. fingers at two metres; without lenses : V.O.S. 6/10. With lenses: V.O.D. 6/60; with lenses V.O.S. 6/10.

A central and paracentral scotoma was discovered on the Bjerrum screen for red, green, and blue.

The edge of the optic disc was hazy on nasal side and the nasal blood-vessels near the disc were indistinct. The left optic disc and fundus were perfectly clear. Examination of the nose showed a deviation of the septum to the right in the region of the middle turbinate, but no sign of hypertrophy or oedema of the mucous membrane was present. No pus was seen and the frontal and maxillary sinuses were clear on transillumination. On account of the central scotoma, history of involvement of the muscles which lie to the inner wall of the orbit, and the history of acute nasal catarrh (although the latter did not occupy a prominent place in her mind) operation was offered. The patient accepted operation and, on August 13, I removed the middle turbinate and opened the sphenoid and posterior ethmoid cells (with Sluder's 
knife). In order to gain space for the operative procedures I first did a sub-mucous resection of the septum. The operation was performed under morphia and scopolamine with local applications of cocaine paste.

At the operation no sign of pus or secretion was seen. The walls of the ethmoid cells and sphenoid sinuses were thin.

After-history : August 13 operation, August 19 nasal condition good. V.O.D. without lenses 6/15-4 (i.e., saw two letters out of six on 6/15 line), central scotoma for green, but the red and blue scotoma was no longer present. The appearance of disc was the same as on August 11.

August $26:$ V.O.D. $=6 / 15-3$. Upper and lower nasal edge of disc not distinct, pink in colour. Lower temporal edge distinct and white. Scotoma for colours no longer present.

September 4: Cloudiness on nasal side of disc disappeared, outline of blood-vessels quite clear, edge of disc more distinct.

September 16 : V.O.D. $=6 / 10-2$; V.O.S. 6/10. Edge of disc clearly defined except that the demarcation between disc and fundus at upper and nasal side not clear, but as the disc on the opposite side presented the same appearance, the patient was discharged as cured. The disease existed one month before the operation and cleared up one month after the operation.

During the last two weeks of after-treatment Hyd. c. cret. 4 grs. with pot. iod. 20 grs. was daily administered (i.e., two weeks after operation), but before any drugs were administered the vision had improved from fingers at two metres to 6/15-4 and the colour scotoma had disappeared.

\section{KRUKENBERG'S SPINDLE IN A CATARACT CASE}

\section{BY}

\section{R. R. JAMES \\ LONDON}

I HAD never seen or heard of a case of Krukenberg's spindle before reading the proofs of Dr. Cardell's paper in the Brit. Jl. of Ophthal. in the April number, Vol: X, p. 198. The following case seems worthy to be recorded briefly :

A.F., a single woman, aged 63 years, attended my out-patients' department at St. George's Hospital, on April 17, 1926, with a mature cataract in her only useful eye. The history, traced from the hospital records, was as follows : She first attended in June, 1889, under the care of $\mathrm{Mr}$. Adams Frost; the notes of this first visit are rather fragmentary, but the vision with pupils dilated 